\title{
Experimental and Numerical Assessment of the Service Behaviour of an Innovative Long-Span Precast Roof Element
}

\author{
Bruno Dal Lago*
}

(Received August 4, 2016, Accepted January 31, 2017, Published online May 22, 2017)

\begin{abstract}
The control of the deformative behaviour of pre-stressed concrete roof elements for a satisfactory service performance is a main issue of their structural design. Slender light-weight wing-shaped roof elements, typical of the European heritage, are particularly sensitive to this problem. The paper presents the results of deformation measurements during storage and of both torsional-flexural and purely flexural load tests carried out on a full-scale $40.5 \mathrm{~m}$ long innovative wing-shaped roof element. An element-based simplified integral procedure that de-couples the evolution of the deflection profile with the progressive shortening of the beam is adopted to catch the experimental visco-elastic behaviour of the element and the predictions are compared with normative close-form solutions. A linear 3D fem model is developed to investigate the torsional-flexural behaviour of the member. A mechanical non-linear beam model is used to predict the purely flexural behaviour of the roof member in the pre- and postcracking phases and to validate the loss prediction of the adopted procedure. Both experimental and numerical results highlight that the adopted analysis method is viable and sound for an accurate simulation of the service behaviour of precast roof elements.
\end{abstract}

Keywords: precast concrete, pre-stressing, roof elements, non-linear modelling, visco-elasticity, full-scale experimentation.

\begin{tabular}{|c|c|c|c|}
\hline \multicolumn{2}{|c|}{ List of notations } & \multirow[t]{2}{*}{$f_{p(0.1) k}$} & \multirow{2}{*}{$\begin{array}{l}\text { Characteristic strength of pre-stressing steel at } \\
0.1 \% \text { of residual strain }\end{array}$} \\
\hline$\varepsilon_{\text {creep }}$ & Strain due to the viscous loss for creep & & \\
\hline$\varepsilon_{e l}$ & Strain due to the elastic loss & $f_{y k}$ & Characteristic yield strength \\
\hline$\varepsilon_{\text {long }}$ & Longitudinal strain & $f_{u k}$ & Characteristic ultimate strength \\
\hline$\varepsilon_{c s}$ & Total shrinkage strain of concrete & $n_{p}$ & Number of pre-stressing tendons \\
\hline$\varphi$ & Creep coefficient of concrete & $q$ & Distributed load \\
\hline$\varphi_{\text {anch }}$ & Anchorage length correction factor & $t$ & Time in days \\
\hline $\begin{array}{l}\varphi_{\chi} \\
\sigma\end{array}$ & $\begin{array}{l}\text { Curvature correction factor } \\
\text { Longitudinal stress }\end{array}$ & $t_{0}$ & $\begin{array}{l}\text { Time in days from the day of release of pre- } \\
\text { stressing }\end{array}$ \\
\hline$\sigma_{p}$ & Pre-stress & $v$ & Vertical deflection \\
\hline \multirow{3}{*}{$\begin{array}{l}\sigma_{p_{0}} \\
\sigma_{c, Q p} \\
\Delta \sigma_{p, c+s+r}\end{array}$} & Initial pre-stress & $z_{c p}$ & Distance between the centre of gravity of the \\
\hline & Stress in concrete surrounding the tendons & & concrete cross-section and the pre-stressing \\
\hline & $\begin{array}{l}\text { Pre-stress loss for combined elasticity, creep, } \\
\text { shrinkage and relaxation }\end{array}$ & $A_{c}$ & $\begin{array}{l}\text { reinforcement } \\
\text { Area of the cross-section of concrete }\end{array}$ \\
\hline$\Delta \sigma_{p r}$ & $\begin{array}{l}\text { Absolute value of the stress losses for relaxation } \\
\text { of pre-stressing tendons }\end{array}$ & $\begin{array}{l}A_{p} \\
E\end{array}$ & $\begin{array}{l}\text { Area of the pre-stressing tendons } \\
\text { Young modulus }\end{array}$ \\
\hline$\Delta P_{\theta}$ & $\begin{array}{l}\text { Absolute value of the load losses for accelerated } \\
\text { hardening temperature effect }\end{array}$ & $\begin{array}{l}E A_{e q} \\
E_{c m j}\end{array}$ & $\begin{array}{l}\text { Equivalent axial stiffness } \\
\text { Mean Young modulus of concrete at day } j\end{array}$ \\
\hline$\theta$ & Beam flexural curvature & $E_{p}$ & Young modulus of pre-stressing steel \\
\hline \multirow[t]{3}{*}{$f_{c k}$} & $\begin{array}{l}\text { Strength; it is also used meaning "function of" } \\
\text { Characteristic concrete compressive strength for }\end{array}$ & $I_{c}$ & $\begin{array}{l}\text { Second moment of the area of the concrete } \\
\text { cross-section }\end{array}$ \\
\hline & cylindrical specimens & $I_{i d}$ & $\begin{array}{l}\text { Ideal second moment of the area of the } \\
\text { homogenised cross-section }\end{array}$ \\
\hline & & $L$ & Span of the member \\
\hline \multirow{4}{*}{\multicolumn{2}{|c|}{$\begin{array}{l}\text { Department of Civil and Environmental Engineering, } \\
\text { Politecnico di Milano, P.za Leonardo da Vinci, 32, } \\
20133 \text { Milan, Italy. } \\
\text { *Corresponding Author; }\end{array}$}} & $L_{\text {anch }, p}$ & Length of de-bonding of the tendons \\
\hline & & $M$ & Bending moment \\
\hline & & $M^{\prime}$ & Maximum bending moment given by pre- \\
\hline & & & stressing \\
\hline \multirow{2}{*}{\multicolumn{2}{|c|}{$\begin{array}{l}\text { E-mail: brunoalberto.dallago@polimi.it } \\
\text { Copyright } @ \text { The Author(s) } 2017 \text {. This article is an open } \\
\text { access publication }\end{array}$}} & $M^{\prime}$ & Maximum bending moment given by \\
\hline & & & gravitational loads \\
\hline
\end{tabular}


$T_{\max }$

Temperature of concrete before the thermal treatment

Maximum temperature during accelerated hardening

\section{Introduction}

The prediction of the deformative behaviour of a prestressed member is in general a challenging design task, due to the combination of several interacting phenomena, among which the conditions of hardening, the relaxation of steel, the creep and the shrinkage of concrete. Wing-shaped precast roof elements used in industrial buildings (Fig. 1) are particularly sensitive to this issue, due to their typical high slenderness associated with lightness.

This issue has been a fascinating research subject with direct field application since the diffusion of pre-stressed concrete and keeps attracting the interest of researchers. A comprehensive overview of the problem is available in Dal Lago (1973) with specific reference to pre-stressed members and in CEB (1984). Martin (1977) introduced the multiplier method for the estimation of long-term camber/deflection in the version most commonly used in normative approaches. More recently, Barr and Angomas (2010) analysed the camber of bridge deck members and compared it with different analytical and numerical methods of estimation, attributing the differences mainly to the effect of temperature. Roller et al. (2011) found an over-estimation of the camber values in time by analysing a bridge member with reference to the American standards. A comparison between experimental deflection and numerical prediction was also performed in Tadros et al. (2011). Breccolotti and Materazzi (2015) performed experimental testing on the deformative behaviour in storage of a widely diffused wing-shaped roof element. The influence of the curing process and thermal history during early stage hardening was described in Roller et al. (2003), Storm et al. (2013) and Lee et al. (2016a, b).

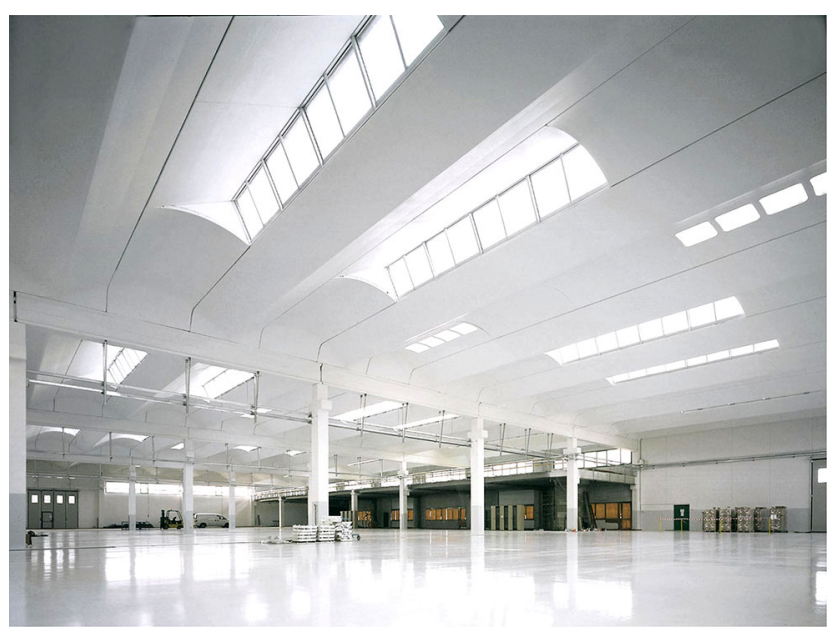

Fig. 1 Industrial building with wing-shaped roof elements.
Rosa et al. (2007) calibrated a visco-elastic model on the basis of a series of field measurements of the camber evolution in bridge girders. A fully coupled sectional-based mechanical model was presented in Pisani (2012) and applied to a case study in Bamonte and Pisani (2015).

The European approach contained in EN 1992-1-1:2005 (2005) (Eurocode 2) is used as a reference. The standards Model Code 2010 (CEB-FIB 2013) and ACI 318 (ACI 2008) provide alternative approaches. Gribniak et al. (2013) provided a comparison among the different standard approaches, stating that Eurocode 2 is usually on the safe side, which means that the predicted long-term deflection values for R.C. beams are higher than the observed. However, for a correct service design of a pre-stressed R.C. beam, the prediction of a higher camber value falls on the unsafe side. Singh et al. (2013) made a comparison of the effect of the different models proposed for concrete hardening on the evaluation of pre-stressing losses of a bridge girder.

Recent research activity specifically devoted to precast structures performed at European level mainly focused on the seismic performances of the structure and the connections (Biondini and Toniolo 2010; Toniolo 2012; Biondini et al. 2013; Colombo et al. 2014; Belleri et al. 2014; Dal Lago et al. 2016b; Ercolino et al. 2016), but also innovative materials attracted growing attention (Crossett et al. 2015; Dal Lago et al. 2016c). The latter subject requires a new definition of the main parameters used for the prediction of the long-term behaviour of the member, or the introduction of explicit mechanical approaches, as suggested by Bischoff (2005) and Knight et al. (2015).

Several authors investigated the behaviour up to failure of wing-shaped precast elements with sophisticated models combining mechanical and geometric non-linearities (Belletti 2009; di Prisco et al. 2012; Belletti et al. 2016) and through experimental testing (Carbonari et al. 2013). Static tests on full-scale precast beams of exceptional length were carried out by Kim et al. (2016).

\section{Wing-Shaped Precast Roof Element Under Investigation}

The service behaviour of an innovative long-span roof element part of a precast system for industrial buildings $\left(\right.$ Ondal $^{\circledR}$, Fig. 2) is studied both experimentally and numerically in this paper. This roofing typology is representative of an important portion of the European heritage of industrial buildings since the late 80s (Dal Lago and Mantegazza 1988) up to today. The novel element has a lightweight Y-shaped cross-section with a depth of $1.5 \mathrm{~m}$ and a width of $2.5 \mathrm{~m}$ with a hollow core positioned at the bottom, which increases the torsional stiffness and resistance with respect to the typical $\mathrm{V}$ shape of the shallower standard element of this system (Breccolotti and Materazzi 2015). The edges of the element are shaped for the connection with the beam. The novel element was engineered to cover spans up to $42 \mathrm{~m}$. 
1) Foundation footing

2) Column with corbels

3) Crane beam TT

4) Roof beam I

5) ONDAL slab member

6) Terminal element

7) Shed shell

8) Barrel-vault shell

9) Barrel-vault shell with skylights

10) Edge adjustable shell

11) Cladding panel

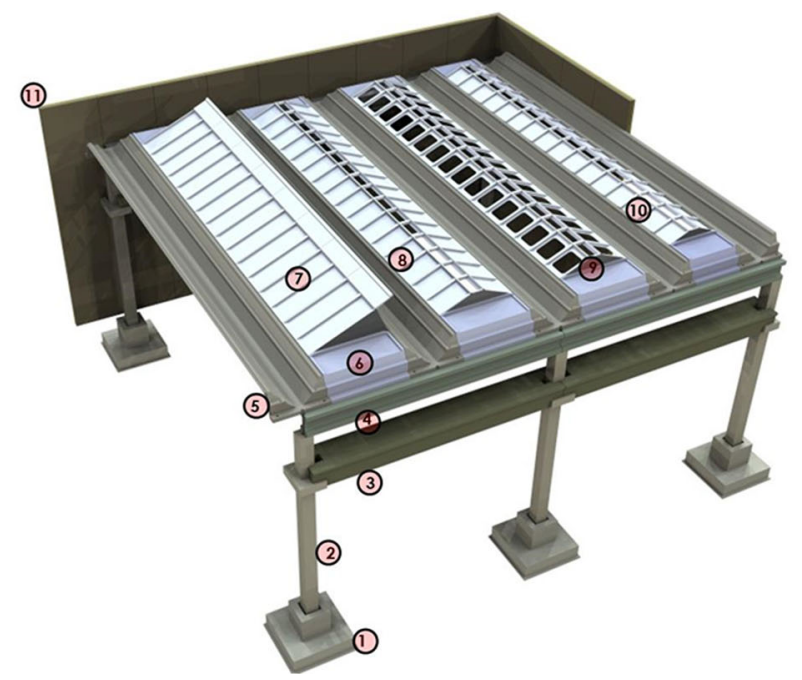

Fig. 2 Components of the Ondal ${ }^{\circledR}$ system for industrial buildings (courtesy of DLC consulting).

An element spanning $40.5 \mathrm{~m}$ was subjected to monitoring in storage and experimental testing. Figure 3 shows the cross-section of the case study element. It was reinforced with $21 \mathrm{~d} 15.2$ main tendons and $6 \mathrm{~d} 12.5$ secondary tendons made of $f_{p(0.1) k} 1860$ pre-stressing steel, all pre-stressed at $1400 \mathrm{MPa}$. Plastic debonding sleeves were applied to selected main strands in order to limit the concrete tension close to the element ends. Grade B450C Mild steel rebars and grade B450A nets were also added. Table 1 lists the longitudinal reinforcement of the element. The transversal reinforcement was made of two welded wire meshes running around the core, for a total of $157 \mathrm{~mm}^{2}$ every $200 \mathrm{~mm}$. Eight U-shaped d12 transversal bars were added at each end with spacing of $38 \mathrm{~mm}$. The concrete used was declared by the producer to be of class C50/60, but crushing tests performed at 28 days by the producer on cubic concrete specimens showed that the actual class was between C55/67 and C60/75. Table 2 contains the main mechanical properties of the materials that were used.
The element was cast in special self-reacting metallic formworks (Fig. 4) made by a fixed bottom mould and a rotating counter-mould with hydraulic opening system (Dal Lago et al. 2016a). The formwork is provided with vibration and heating systems for the accelerated hardening of SCC. The pre-stressing system is hydraulic with the use of prestressing tendons linked to the pulling system through steel wedges.

Figure 5 shows pictures of an industrial building using the roof element under investigation in phase of assemblage.

\section{Behaviour in Storage}

The check of camber and shortening of pre-stressed manufacts in the phase of storage is an important practice for the quality check of the product and an important potential alarm of design or technological problems.

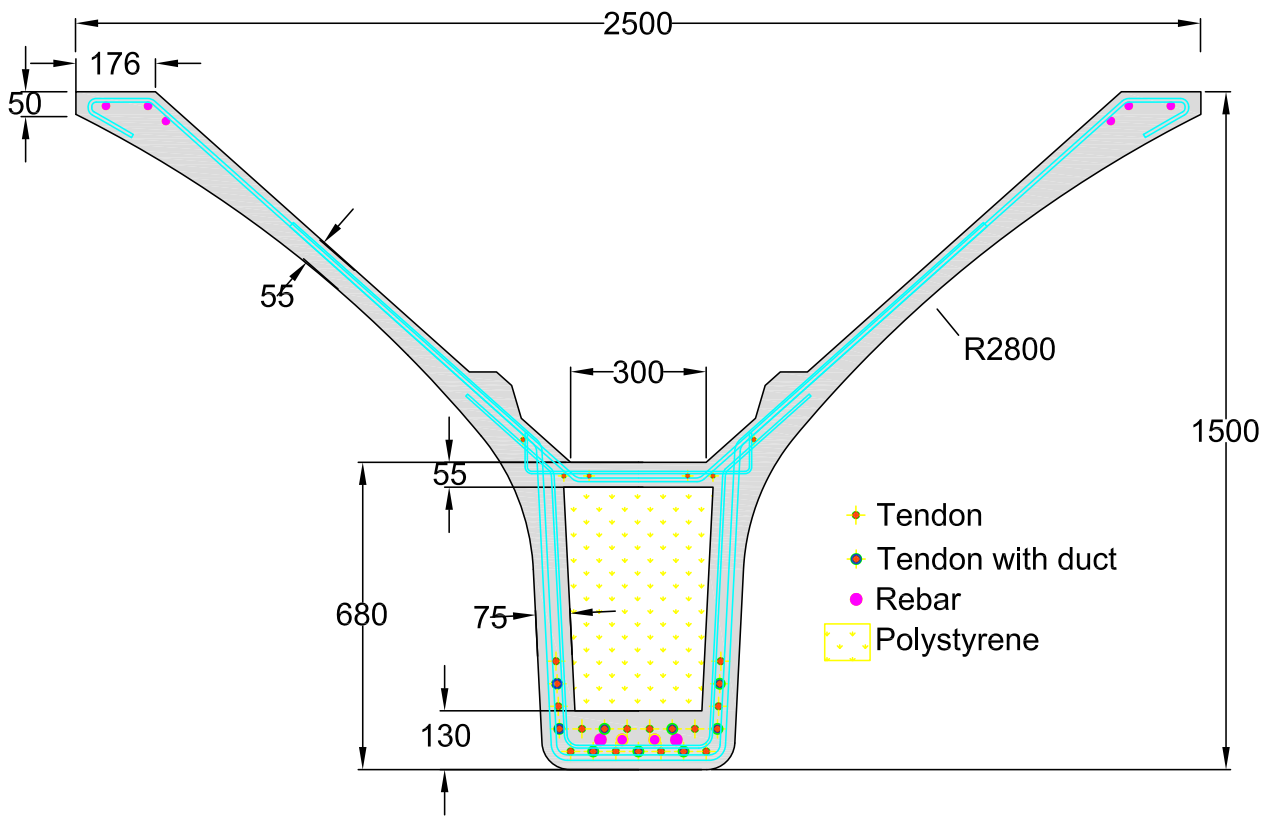

Fig. 3 Wing-shaped precast roof element under investigation. 
Table 1 Longitudinal reinforcement of the case study roof element.

\begin{tabular}{|c|c|c|c|c|}
\hline \multicolumn{5}{|c|}{ Longitudinal reinforcement } \\
\hline No. tendon/bar & Tendon/bar & Material & $\begin{array}{l}\text { Position from the soffit } \\
\text { (mm) }\end{array}$ & $\begin{array}{l}\text { De-bonding sleeve length } \\
\text { from ends }(\mathrm{mm})\end{array}$ \\
\hline $4 \times$ & $7 \mathrm{w} \mathrm{d} 15.2$ & Pre-stressing steel & 40 & 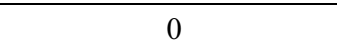 \\
\hline $3 \times$ & $7 \mathrm{w} \mathrm{d} 15.2$ & Pre-stressing steel & 40 & 7000 \\
\hline $4 \times$ & $\Phi 25$ & $\mathrm{~B} 450 \mathrm{C}$ & 65 & 0 \\
\hline $4 \times$ & $7 \mathrm{w} \mathrm{d} 15.2$ & Pre-stressing steel & 90 & 0 \\
\hline $2 \times$ & $7 \mathrm{w} d 15.2$ & Pre-stressing steel & 90 & 5500 \\
\hline $2 \times$ & $7 \mathrm{w}$ d 15.2 & Pre-stressing steel & 90 & 3000 \\
\hline $2 \times$ & $7 \mathrm{w} \mathrm{d} 15.2$ & Pre-stressing steel & 140 & 0 \\
\hline $2 \times$ & $7 \mathrm{w}$ d 15.2 & Pre-stressing steel & 190 & 1500 \\
\hline $2 \times$ & $7 \mathrm{w} \mathrm{d} 15.2$ & Pre-stressing steel & 240 & 0 \\
\hline $4 \times$ & $7 \mathrm{w} \mathrm{d} 12.7$ & Pre-stressing steel & 650 & 0 \\
\hline $2 \times$ & $7 \mathrm{w} \mathrm{d} 12.7$ & Pre-stressing steel & 730 & 0 \\
\hline $2 \times$ & $\Phi 16$ & $\mathrm{~B} 450 \mathrm{C}$ & 1435 & 0 \\
\hline $4 \times$ & $\Phi 16$ & B450C & 1469 & 0 \\
\hline
\end{tabular}

Table 2 Material properties.

\begin{tabular}{c|c|c|c|c}
\hline Material & Concrete & Pre-stressing steel & Mild steel & Net steel \\
\hline Class & C55/67-C60/75 & $\mathrm{f}_{\mathrm{p}(0.1) \mathrm{k}} 1860$ & B450C & B450A \\
\hline $\mathrm{E}(\mathrm{GPa})$ & 37 & 195 & 210 & 210 \\
\hline $\mathrm{f}_{\mathrm{yk}}(\mathrm{MPa})$ & - & 1860 & 450 & 450 \\
\hline $\mathrm{f}_{\mathrm{uk}}(\mathrm{MPa})$ & - & 2067 & 540 & 540 \\
\hline $\mathrm{f}_{\mathrm{ck}}(\mathrm{MPa})$ & 58 & - & - & - \\
\hline$\varepsilon_{\mathrm{u}}(\%)$ & 0.35 & 2.00 & 7.50 & 2.50 \\
\hline
\end{tabular}

\subsection{Theoretical Background}

A time-step procedure was implemented for the correct estimation of the deformative behaviour of pre-stressed elements in visco-elastic range. The procedure is based on the time-step evaluation of the visco-elastic phenomena linked to the member longitudinal shortening and its subsequent deflection profile. The geometrical non-linearity of the problem displays due to the following considerations:

- The pre-stressing reinforcement generates a constantly distributed moment distribution which is linearly depending on the stress of the strands and, if properly designed, leads to an upward deflection profile in service with camber at mid-span, subjected to a visco-elastic behaviour in time: $v=f\left(\sigma_{p}, \varphi\right)$.

- A longitudinal visco-elastic shortening of the member due to the axial load induced by the pre-stressing leads to elastic losses in the strands, whose axial stress is lowered after shortening: $\sigma_{p}=f(\varphi)$.

- Since the deflection profile of the member depends on both longitudinal deformation and deflection profiles, both visco-elastically evolving, the two are coupled: $v=f\left[\sigma_{p}(\varphi), \varphi\right]$.

Furthermore, the viscous axial shortening of pre-stressed elements is particularly relevant, since they are subjected to strong axial loads applied in an early stage of concrete hardening due to the daily schedule typical of the industrial production.

With reference to the behaviour in storage of pre-stressed elements, the elastic contribution always has a monotonic decreasing tendency, due to the combination of the following phenomena:

- visco-elastic shortening of the element and subsequent elastic losses in the bars,

- relaxation of the pre-stressing reinforcement,

- shrinkage of concrete,

while the creep contribution, if the elastic component is always positive, is also always positive with a monotonic increasing trend. The combination of those terms determines the overall deformation behaviour of the element, which could also be subjected to trend reversal of the deflection in 


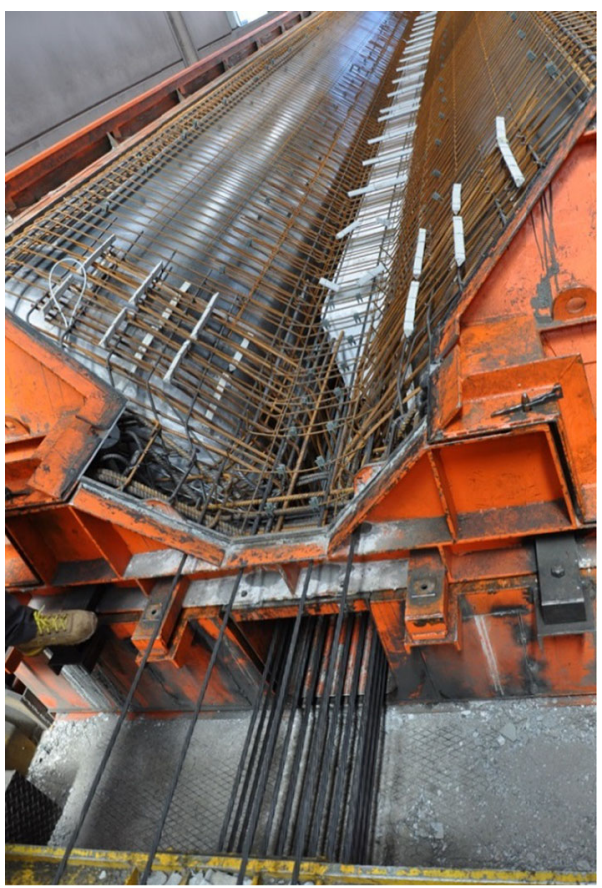

Fig. 4 Particular view of the end of the mould with mild and pre-stressing steel reinforcement ready for casting.
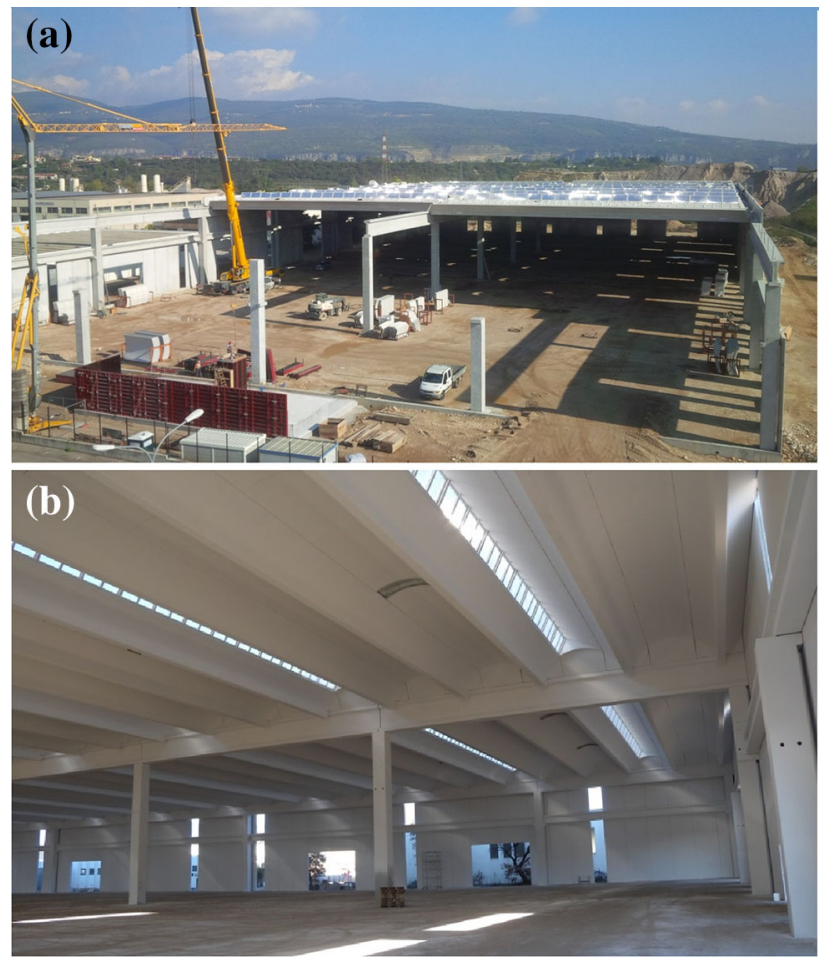

Fig. 5 Assemblage of a precast industrial building with the case study roof element (courtesy of Angelo Basso): aerial view (a), internal view (b).

the range of downwards values, difficultly predictable without an accurate evaluation of the element shortening evolution in time.

The employed methodology solves the problem by means of semi-analytical techniques through a discretisation in the time domain, under the hypotheses of plane sectional strain profile and homogeneous section. In particular, the longitudinal behaviour of the element and its deflection profile are considered as uncoupled, and the formulation is corrected with linear terms in order to take into account in a simplified way the real coupling. As a consequence of such an hypothesis, it is possible to formulate the longitudinal shortening first, and subsequently compute the deflection history as a function of the shortening tendency.

The deflection profile of a member is calculated in accordance with the well-known visco-elastic model having the integral form of Eq. (1) (see Branson 1977; Migliacci and Mola 1985, Mola 1997; Ghali et al. 2011; Mola and Pellegrini 2012):

$$
v\left(t, t_{0}\right)=v_{e}(t)+\int_{t_{0}}^{t} v_{e}(t) \dot{\phi}\left(t, t_{0}\right) d t
$$

where the visco-elastic deflection $v$ at time $t$ is expressed as the sum of a contribution of the elastic deformation computed at time $t$ to which the contribution of creep, depending on the first derivative of the creep coefficient $\varphi\left(t, t_{0}\right)$, has to be summed. A similar equation defines the visco-elastic longitudinal strain equation for pre-stressed members with constant cross-section [Eq. (2)], depending on the elastic [Eq. (3)], creep [Eq. (4)] and shrinkage strains:

$$
\begin{aligned}
& \varepsilon_{\text {long }}\left(t, t_{0}\right)=\varepsilon_{\text {el }}\left(t, t_{0}\right)+\varepsilon_{\text {creep }}\left(t, t_{0}\right)+\varepsilon_{c s}(t) \\
& \varepsilon_{\text {el }}\left(t, t_{0}\right)=\frac{\sigma_{p}\left(t, t_{0}\right) A_{p}}{E_{\text {cmj }}(t) A_{c}} \phi_{\text {anch }} \\
& \varepsilon_{\text {creep }}\left(t, t_{0}\right)=\int_{t_{0}}^{t} \varepsilon_{\text {el }}(t) \dot{\phi}\left(t, t_{0}\right) d t
\end{aligned}
$$

where the mean stress in the pre-stressing reinforcement can be defined as per Eq. (5), taking into account the relaxation, thermal and shortening losses:

$$
\begin{aligned}
\sigma_{p}\left(t, t_{0}\right)= & \sigma_{p 0}\left(1-\phi_{\chi} A_{p} \frac{z_{c p}^{2}}{I_{i d}}\right)-\Delta \sigma_{p r}(t)-\frac{\Delta P_{\theta}}{A_{p}} \\
& -\varepsilon_{\text {long }}\left(t, t_{0}\right) E_{p}
\end{aligned}
$$

where an anchorage factor $\varphi_{\text {anch }}$ is simply defined in average terms for the distribution of debonding sleeves and anchorage of the cables [Eq. (6)]:

$$
\phi_{\text {anch }}=\frac{\sum_{p}\left[L-L_{\text {anch }, p} \frac{\sigma_{p 0}}{\operatorname{mean}\left(\sigma_{p 0}\right)}\right]}{\operatorname{Ln}_{p}}
$$

and $\varphi_{\chi}$ is a weighted factor for curvature loss taking into account the combination of parabolic-shaped deformation profile due to pre-stressing and fourth order polynomial function deformation profile due to distributed loads (selfweight), to which the maximum bending moments $M^{\prime}$ e $M^{*}$, respectively, belong [Eq. (7)]. The $\varphi_{\chi}$ factor is always lower than unity. 


$$
\phi_{\chi}=\frac{v_{\max , \mathrm{p}}}{v_{\max , \mathrm{q}+\mathrm{p}}}=\left(1+\frac{5 M *}{6 M^{\prime}}\right)^{-1}
$$

The non-linearity of Eq. (2) is clear, due to the presence of the unknown $\varepsilon_{\text {long }}$ in the integral belonging to the creep term. The solution is not achievable in closed form, and the equation needs to be solved with the aid of numerical techniques.

It is though possible to identify an approximated solution with independent variables estimating the loss for shortening of the member, through a fictitious stiffening of the axial deformability.

By eliminating the unknown from the formulation of $\sigma_{p}$ [Eq. (8)]:

$$
\sigma_{p}(t)=\sigma_{p 0}\left(1-\phi_{\chi} A_{p} \frac{z_{c p}^{2}}{I_{i d}}\right)-\Delta \sigma_{p r}(t)-\frac{\Delta P_{\theta}}{A_{p}}
$$

and by making its contribution explicit in the equation of the elastic deformation $\varepsilon_{e l}$, the latter can be written as follows [Eq. (9)]:

$$
\varepsilon_{e l}\left(t, t_{0}\right)=\frac{\sigma_{p}(t) A_{p}}{E_{c m j}(t) A_{c}} \phi_{a n c h}-\frac{\varepsilon_{e l}\left(t, t_{0}\right)\left[1+\phi\left(t, t_{0}\right)\right] E_{p} A_{p}}{E_{c m j}(t) A_{c}}
$$

By operating the proper simplifications, it is then possible to define the elastic deformation term $\varepsilon_{e l}$ as per Eq. (10):

$$
\varepsilon_{e l}\left(t, t_{0}\right)=\frac{\sigma_{p}(t) A_{p}}{E A_{e q}\left(t, t_{0}\right)} \phi_{\text {anch }}
$$

defining the equivalent axial stiffness $E A_{e q}$ as follows [Eq. (11)]:

$$
E A_{e q}\left(t, t_{0}\right)=E_{c m j}(t) A_{c}+E_{p} A_{p}\left[1+\phi\left(t, t_{0}\right)\right]
$$

In this way, the integral equation is fully explicit and can be solved without the need of iteration.

\subsection{Application}

The deformation of the case study element during its storage phase was monitored with low precision instruments (rolling tape for shortening and analogue deflection gauge for mid-span deflection), typical of the standard control of production, having as objective a global check. Figure 6 reports the measures.

The above-described numerical procedure was applied to the roof element under investigation. In order to make its solution comparable with the simplified formulation of EN 1992-1-1:2005 (2005) (Eurocode 2), all data related to timedependent properties of materials was taken from that standard. The numerical curves related to the evolution in time of axial shortening and mid-span deflection are reported in Fig. 6 in comparison with the experimental measurements. The axial behaviour is well predicted by the numerical algorithm, and the deflection shows a tendency to stabilise on a plateau, in accordance with the experimental data, but

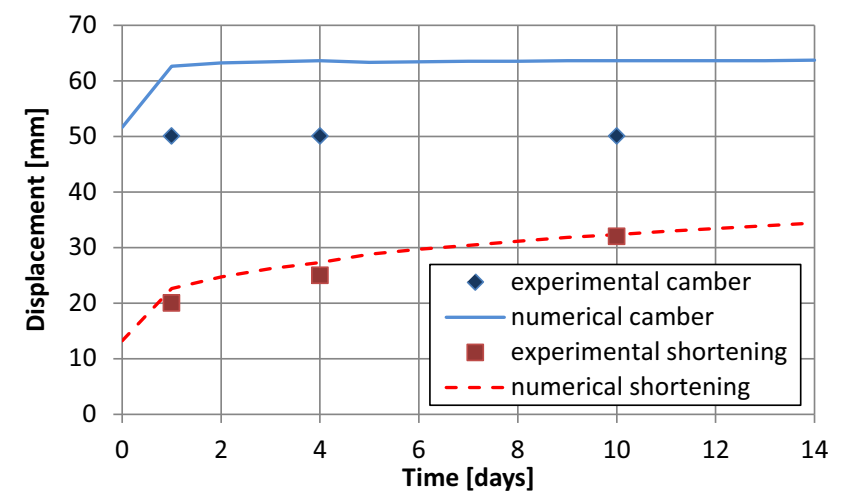

Fig. 6 Numerical prediction of mid-span camber and shortening time history compared with experimental measures.

on a slightly over-estimated value. It can be observed that the difference between the numerical and experimental plateau value of the mid-span camber, of about $14 \mathrm{~mm}$, is limited to only $1 / 3000$ of the span.

EN 1992-1-1:2005 (2005) part 1-1 provides a closed formulation for the calculation of elastic and time-dependant losses in accordance with the multiplier method, reported in Eq. (12):

$$
\Delta \sigma_{p, c+s+r}=\frac{\varepsilon_{c s} E_{p}+0,8 \Delta \sigma_{p r}+\frac{E_{p}}{E_{c m}} \phi\left(t, t_{0}\right) \sigma_{c, Q p}}{1+\frac{E_{p} A_{p}}{E_{c m} A_{c}}\left(1+\frac{A_{c}}{I_{c}} z_{c p}^{2}\right)\left[1+0,8 \phi\left(t, t_{0}\right)\right]}
$$

The prediction of the evolution in time of the deformation calculated in accordance with this simplified criterion leads to a curve that is sensibly different from that obtained with the proposed formulation, with a relevant under-estimation of the mean pre-stressing losses, to which a larger camber of the element in time is associated. Figure 7 shows the comparison of the two loss curves plotted with a logarithmic function of the time. At the day of execution of the tests, 14 days from casting, the mean pre-stressing loss estimated through the time-step proposed formulation is equal to $15.0 \%$, while the simplified formulation leads to $11.7 \%$ of loss.

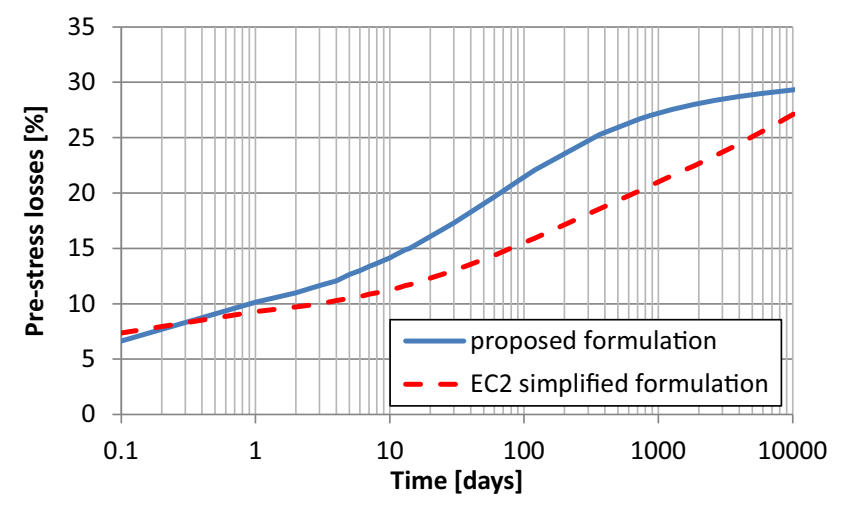

Fig. 7 Evolution of pre-stressing losses in time: comparison of the adopted explicit integral formulation and the simplified formulation of EC2. 


\section{Load Tests and Numerical Simulations}

\subsection{Test Setup}

The roof element monitored in storage was later subjected to load testing at the Antonio Basso company production plant in Treviso, Italy. Two loading tests were carried out in order to verify the mechanical behaviour of the element under combined flexure and torsion in elastic field and under pure flexure in pre- and post-cracking fields. Figure 8 shows sketches of the loading apparatus and of the measurement setup. Pictures of the experimental setup are shown in Figs. 9 and 10 shows particular views of the instrumentation. 30 hydraulic jacks were used in parallel to apply a quasi-uniformly distributed load to the element. They have been positioned along ten sections distanced by $3.70 \mathrm{~m}$ and connected at each section at both wing edges and at the centre. Repartition steel beams were placed at the edges to better distribute the load. The jacks were connected with bundles of rebars placed underneath the element, used as counter-acting weight, having an approximated global mass equal to 60 tons. One vertical displacement transducer was positioned in correspondence of each of the jacks positioned at the quarters of the span, for a total of nine vertical LVDTs, with three additional horizontal transducers placed at the top of the element at the quarters of the span with the aim to measure the relative opening of the wings. The vertical displacements are subtracted to the small deformation of the element in correspondence of the supports, measured by two vertical LVDTs with short stroke. The load tests were carried out by 4EMME (Altinier 2015).

\subsection{Combined Flexure-Torsion Test}

The first test carried out was the one of combined flexure and torsion, where the load was applied to one row of jacks placed in correspondence of one wing only. In such a way, the vertical load was applied with an eccentricity equal to half of the width of the element with respect to its centre of the mass. The test is aimed at simulating the positioning of the structural completing shells on top of the roof element (Fig. 2), which is typically performed one span per time, studying the stability of the element under this temporary load condition.

Under an equivalent distributed load of $1.66 \mathrm{kN} / \mathrm{m}$, a maximum torsional rotation of $0.23 \mathrm{rad}$ was measured at mid-span, together with a wing distancing limited to half a millimetre in the same section. This shows the efficiency of the full collaboration of the cross-section. A computer model using 8-node hexahedra brick elastic elements (32 elements were used to describe the cross-section, each $250 \mathrm{~mm}$ long, for a total of 5248 brick elements) was developed with Straus7 (G+D Computing 2010) for the simulation of the test. The end shaping of the element provides a torsional

(a)
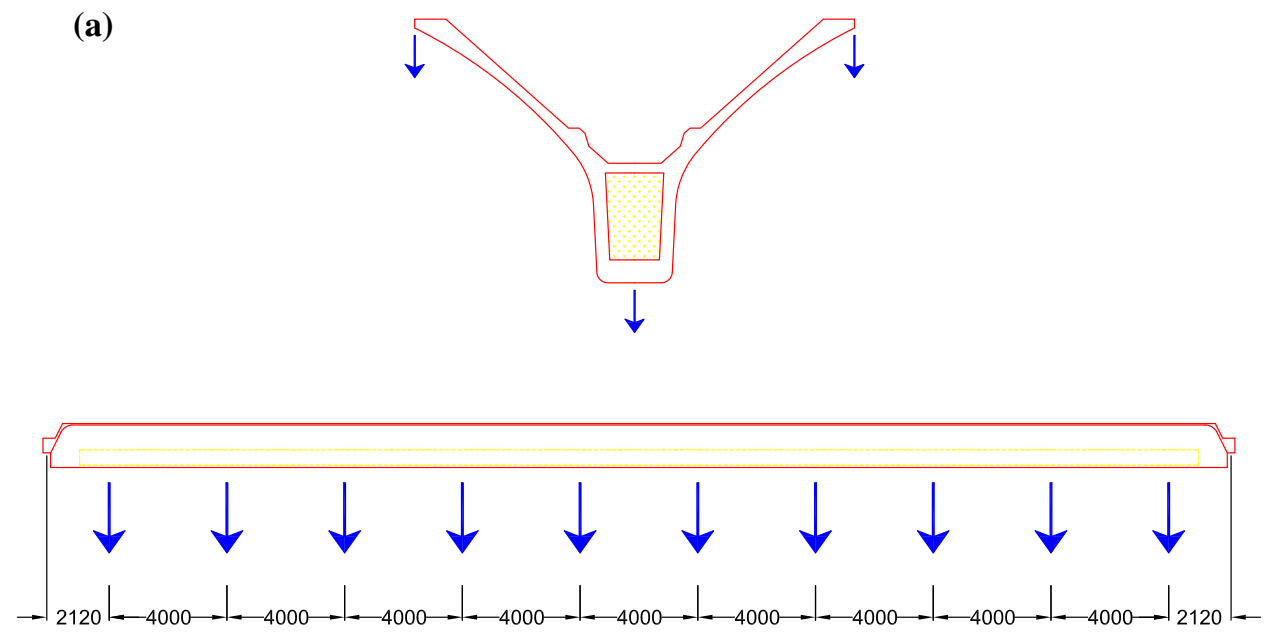

(b)
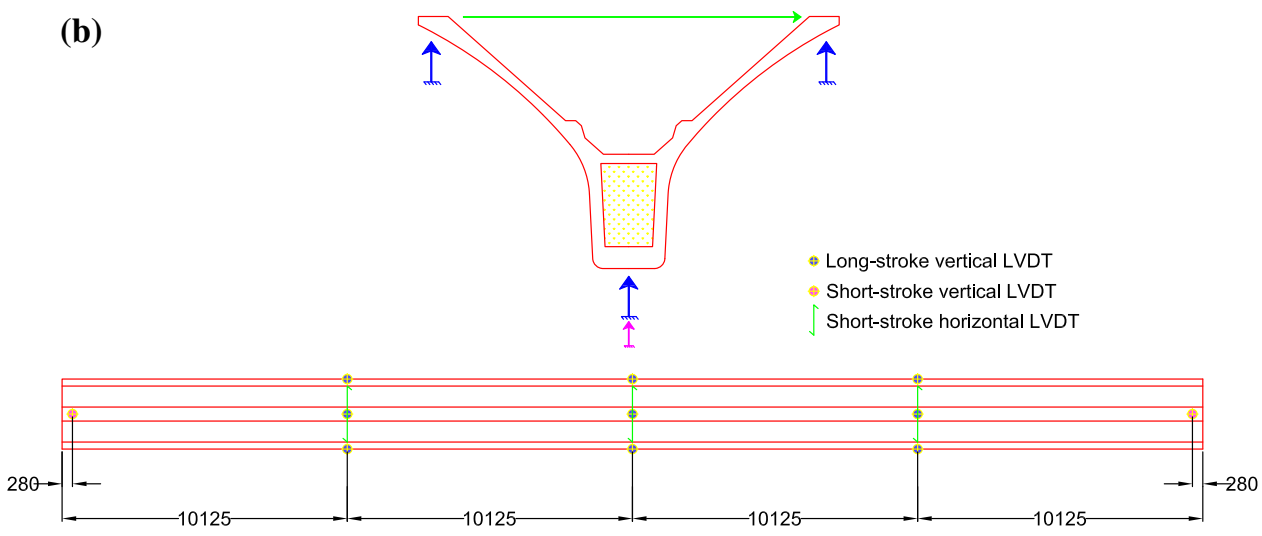

Fig. 8 Test setup: positioning of loading apparatus (a) and instrumentation (b). 

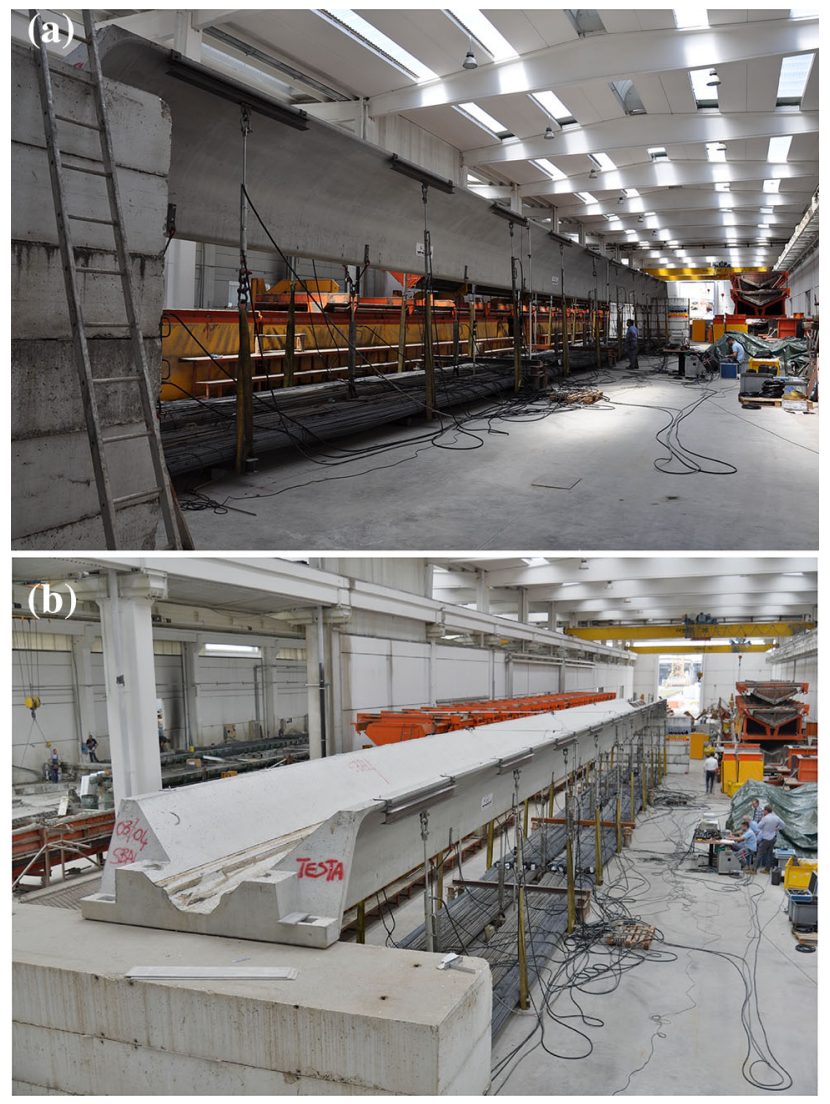

Fig. 9 Test setup views: from the bottom (a) and from the top (b).

clamp at the element ends, which in real constructions is also enhanced by distanced dowels, not used in the load test. The deformation profile of the mid-span cross-section of the beam torsionally clamped at the supports is shown in Fig. 11. Using an elastic modulus equal to $37 \mathrm{GPa}$, which was obtained from the elastic modulus growth curve in time provided by EC2 for a concrete in between classes C55/67 and $\mathrm{C} 60 / 75$ at 14 days, the numerical simulation provides vertical displacements equal to $12-17-21 \mathrm{~mm}$ in the monitored points. This displacement profile yields to a torsional rotation angle of $0.21 \mathrm{rad}$, which is close to the measured one.

\subsection{Flexure test}

The flexure test has been carried out by applying the same oil pressure to all hydraulic jacks. The graph of Fig. 12 shows the experimental equivalent distributed load versus mean mid-span deflection calculated as the average of the three measurements taken at wings and centre. Two load cycles were performed.

After an elastic branch in which all sections of the element were fully compressed, cracking was attained at about $10 \mathrm{~N} /$ $\mathrm{mm}$, after which the experimental curve shows a softening tendency due to the diffusion of cracking from mid-span towards the supports.

A picture of the mid-span area of the element with the flexural crack pattern post-marked with the aid of the computer is shown in Fig. 13a. The cracks were all of modest opening and difficult to be observed.

The test was interrupted at the attainment of an equivalent distributed load of $14.0 \mathrm{~N} / \mathrm{mm}$ (the SLS load for this element was calculated to be $10.0 \mathrm{~N} / \mathrm{mm}$ ), due to the uplift of the counter-acting strand bundles. Cracks at mid-span reached a height of about $600 \mathrm{~mm}$ from the bottom (Fig. 13a). The maximum wing opening was measured equal to $13 \mathrm{~mm}$ at mid-span, corresponding to practically negligible shallowing. The element, once the load was removed, showed negligible residual deflection and completely closed the cracks developed during the test, which suggests that the strands were not plasticised.

A non-linear semi-analytical mechanical model was implemented with the aim to compare the experimental results. The model is based on the evaluation of the non-
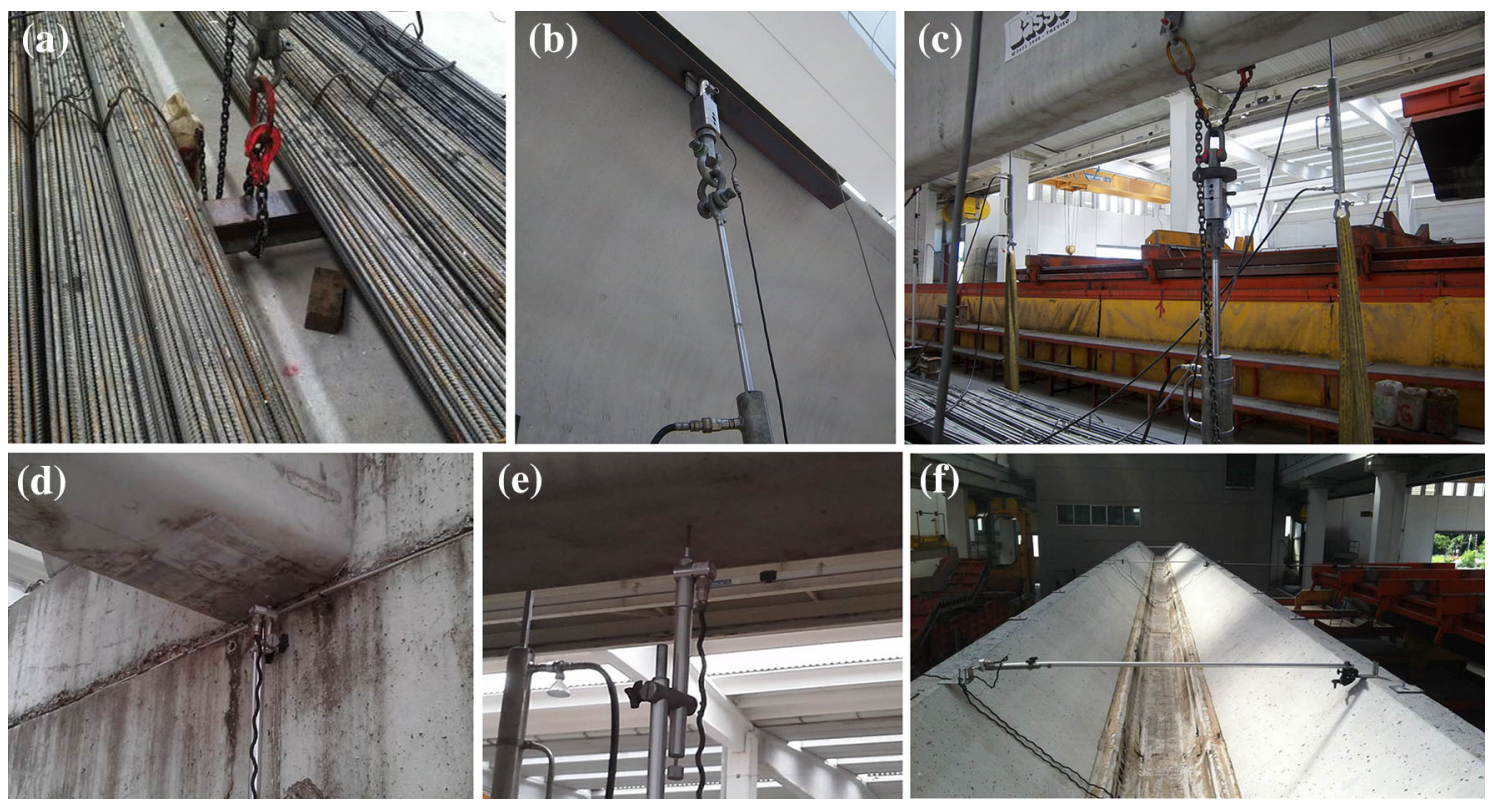

Fig. 10 Test instrumentation: counter-weight bundles of steel bars (a), edge ram, load cell and load repartition beam (b), central ram and load cell (c), end short-stroke LVDT (d), central long-stroke LVDT (e), wing opening LVDTs (f). 


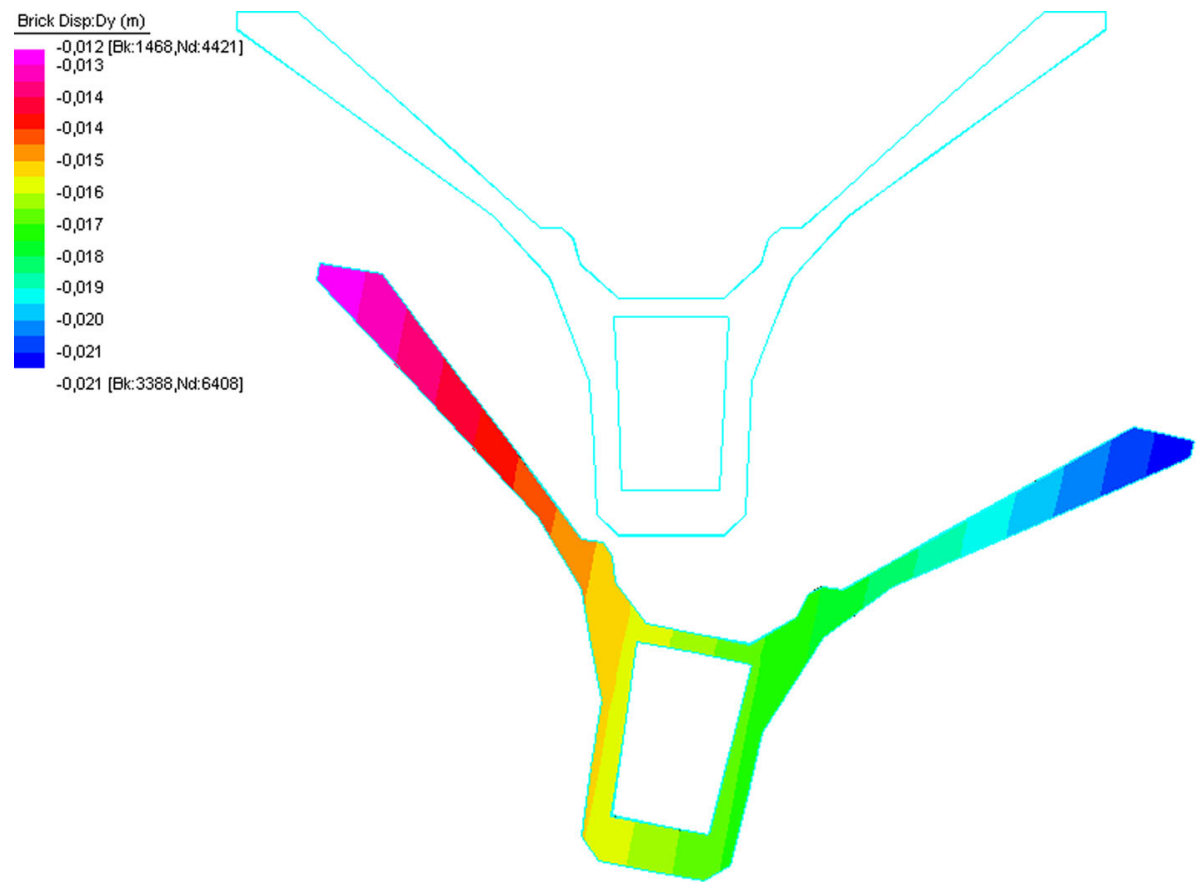

Fig. 11 Numerical simulation of the combined flexure-torsion test: deformed shape of the mid-span cross-section.

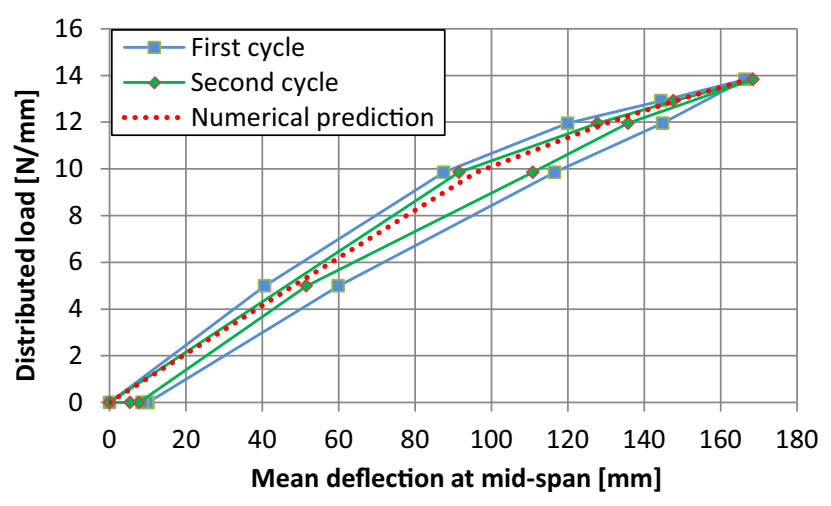

Fig. 12 Flexure test: distributed load versus mid-span deflection.

linear moment vs curvature diagram of the current crosssection in pre-stressed concrete and on the later solution of the equation of the inelastic curve. A Sargin model (Sargin 1971) was used to model concrete in compression considering the above deduced base compressive strength (Fig. 14a), an elastic-plastic model with parabolic plastic branch was used for grade B450C mild steel (Fig. 14b) and an elastic-plastic relationship with linear hardening was used for pre-stressing steel having $f_{p(0.1) k}$ equal to $1860 \mathrm{MPa}$ (Fig. 14c). The strength values were not divided by safety coefficients, in order to catch the experimental behaviour of the element.

Figure 15a shows the non-linear moment vs curvature diagrams of the cross-section corresponding to mean prestressing losses equal to 0,15 and $30 \%$ obtained through the solution of the translational and rotational equilibria of the section neglecting the tensile strength of concrete. It can be observed that, as well known by the designers, the prestressing losses do not influence neither the resistance of the element nor its ductility, due to the plastic properties of steel.
To be noted that the analytical model developed does not take into account possible preliminary failures due to local instability. On the contrary, a relevant influence of the losses is observed with respect to the cracked moment, diminishing with higher losses, which is a fundamental parameter for a good behaviour of the manufact in service. The expected concrete stress distribution along the depth of the section is reported in Fig. 13b either considering or neglecting the tensile strength of concrete. A better correspondence with the height attained by the cracks observed on the element is obtained considering the tensile strength of concrete. It can be observed that the expected crack moment $M_{\text {crack }}$ of the section with mean losses of $15 \%$, as estimated in the previous paragraph after 14 days of ageing, is equal to about $4000 \mathrm{kNm}$. The uniformly distributed load corresponding to first cracking at mid-span is equal to $q_{\text {crack }}=8 M_{\text {crack }} /$ $L^{2}=19.5 \mathrm{~N} / \mathrm{mm}$. In the experimental curve obtained with the flexure test an inflection point corresponding to cracking initiation is observed for a load of about $10 \mathrm{~N} / \mathrm{mm}$ (Fig. 12). By subtracting to the total load the structural self-weight, equal to $10.0 \mathrm{~N} / \mathrm{mm}$, which is already acting before the test, the crack load is estimated with good precision. This confirms the estimation of about $15 \%$ of losses, providing a validation of the results of the time-step numerical procedure illustrated above.

The numerical prediction matches with good precision the experimental curve corresponding to the second cycle, slightly underestimating the cracked stiffness of the first cycle which is larger due to the contribution of the tensile strength of concrete, not anymore playing a role in the second cycle. The obtained non-linear moment vs curvature diagram is used to get the deflection profile of the element by solving the inelastic curve formula $\mathrm{v} "=\theta(\mathrm{M})$ governed by a 2 nd order differential equation. Figure $15 \mathrm{~b}$ shows the numerical deflection profile corresponding to the application 


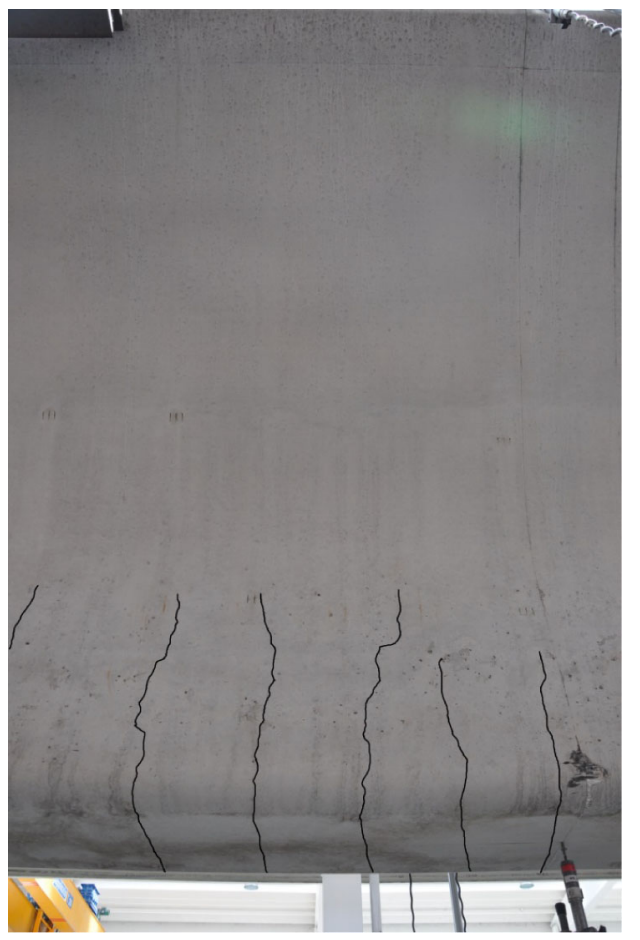

(a)

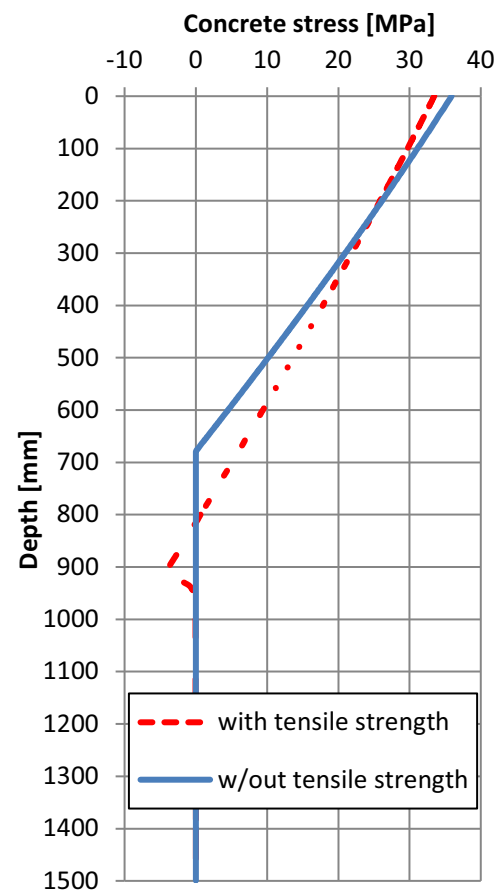

(b)

Fig. 13 Flexural cracking at maximum load: marked distributed cracks in the mid-span region of the member (a), corresponding concrete stress distribution from the numerical prediction with and without tensile strength of concrete (b).

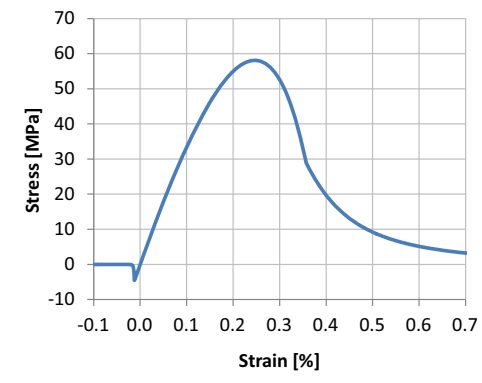

(a)

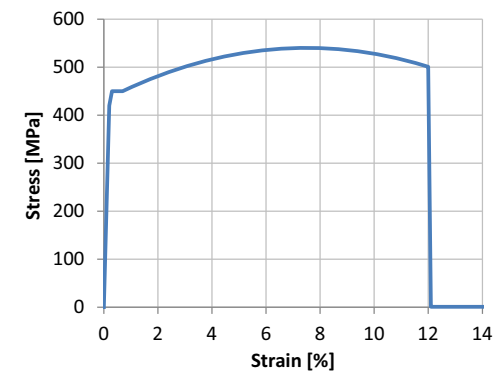

(b)

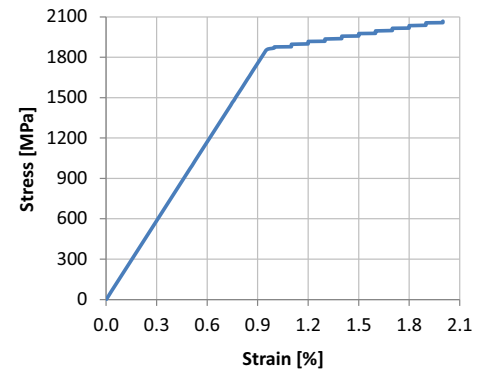

(c)

Fig. 14 Non-linear material properties for: concrete (a), mild steel (b) and pre-stressing steel (c).

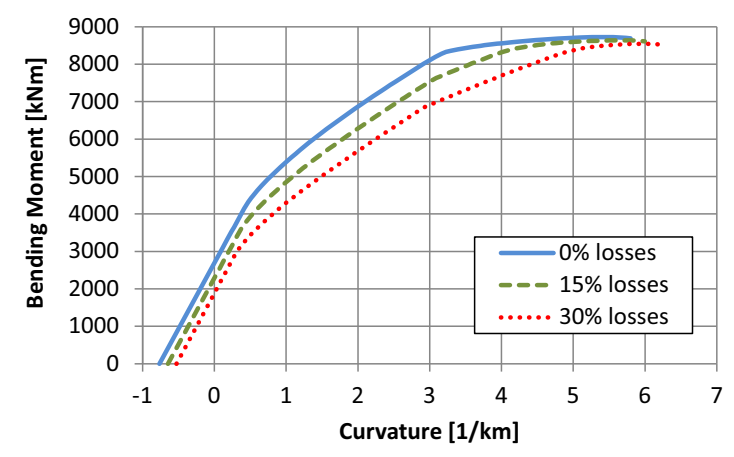

(a)

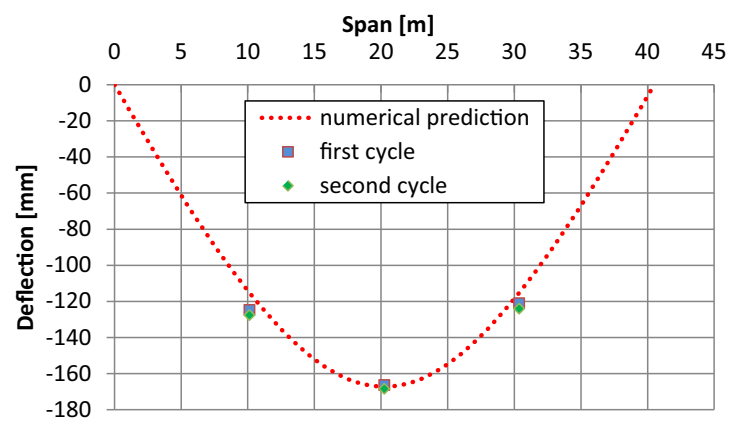

(b)

Fig. 15 Non-linear moment versus curvature diagrams with different values of pre-stressing losses (a), numerical deflection profile compared with the experimental results $(\mathbf{b})$. 
of $24 \mathrm{~N} / \mathrm{mm}$, equal to the sum of the structural weight load and the maximum equivalent distributed load given by the jacks, depurated by the pre-camber. The experimental points included in the graph show that the estimation is sound.

\section{Conclusions}

The service behaviour of an innovative wing-shaped precast roof element was experimentally investigated by means of deformation monitoring during its storage phase and of both torsional-flexural and purely flexural load tests. The results of the load tests show that the element, even if characterised by a relevant slenderness, is scarcely subjected to cross-section distortion under both loading conditions.

An element-based mechanical formulation was implemented to predict the visco-elastic behaviour of pre-stressed concrete members with constant cross-section. It is based on a time-step integral formulation explicitly taking into account the coupling of creep and shrinkage of concrete and relaxation of steel for the determination of pre-stressing losses and both axial deformation and deflection profiles over time. The application of this model to the case study brings to a sound estimation of the experimental deformation profiles. The results of the linear $3 \mathrm{D}$ fem model used to investigate the torsional-flexural behaviour of the element are also in good agreement with the experimental observation. The non-linear mechanical model used for the estimation of the crack load and the deflection profile of the beam in post-cracking phase is able to catch the experimental measurements and provides further confirmation of the validity of the formulation adopted for the estimation of pre-stressing losses over time and the subsequent deflection profile.

The non-negligible scatter between the losses in time predicted with the proposed formulation and the simplified one provided by Eurocode 2 based on the close-form multiplier method suggests that further studies should be carried out in this field.

\section{Acknowledgements}

DLC Consulting of Milan, Italy, is acknowledged for the design and engineering of the roof member studied in the paper, in particular Alberto Dal Lago and Uberto Marchetti. The production of the member subjected to testing and the assemblage of the first buildings made with the system were carried out by Antonio Basso precast company of Treviso, Italy. Special thanks go to Angelo Basso for his deep interest in the development of the work. Dr Francesco Foti from Politecnico di Milano is acknowledged for his contribution in the definition of the visco-elastic semi-analytical model. Dr. Patrick Bamonte from Politecnico di Milano is also acknowledged for his suggestions. Finally, the testing company 4EMME of Treviso, Italy, is acknowledged for the execution of the experimental load tests.

\section{Open Access}

This article is distributed under the terms of the Creative Commons Attribution 4.0 International License (http://creativecommons.org/licenses/by/4.0/), which permits unrestricted use, distribution, and reproduction in any medium, provided you give appropriate credit to the original author(s) and the source, provide a link to the Creative Commons license, and indicate if changes were made.

\section{References}

ACI (American Concrete Institute). (2008). ACI 318-08: Building code requirements for structural concrete and commentary. Farmington Hills, MI: Committee 318, American Concrete Institute.

Altinier, D. (2015). Prova di carico - tegolo tipo BigOndal. Load test report No. 3498/TV, 4emme (pp. 24).

Bamonte, P., \& Pisani, M. A. (2015). Creep analysis of compact cross-sections cast in consecutive stages-Part 2: Algebraic models. Engineering Structures, 96, 178-189.

Barr, P. J., \& Angomas, F. (2010). Differences between calculated and measured long-term deflections in a prestressed concrete girder bridge. Journal of Performance of Constructed Facilities, 24(6), 603-609.

Belleri, A., Torquati, M., \& Riva, P. (2014). Seismic performance of ductile connections between precast beams and roof elements. Magazine of Concrete Research, 66(11), $553-562$.

Belletti, B. (2009). Evaluation of the interaction effects in coupled thin walled prestressed concrete roof elements. European Journal of Environmental and Civil Engineering, 13(6), 745-764.

Belletti, B., Bernardi, P., \& Michelini, E. (2016). Behavior of thin-walled prestressed concrete roof elements-Experimental investigation and numerical modelling. Engineering Structures, 107, 166-179.

Biondini, F., Dal Lago, B., \& Toniolo, G. (2013). Role of wall panel connections on the seismic performance of precast structures. Bulletin of Earthquake Engineering, 11, 1061-1081.

Biondini, F., \& Toniolo, G. (2010). Experimental research on seismic behavior of precast structures. Italian Cement Industry, 854, 74-79.

Bischoff, P. H. (2005). Re-evaluation of deflection predictions for concrete beams reinforced with steel and FRP bars. Journal of Structural Engineering, ASCE, 131(5), 752-767.

Branson, D. E. (1977). Deformation of concrete structures. New York: McGraw-Hill.

Breccolotti, M., \& Materazzi, A. M. (2015). Prestress losses and camber growth in wing-shaped structural members. PCI Journal, 60(1), 98-117. 
Carbonari, S., Gara, F., Roia, D., Leoni, G., \& Dezi, L. (2013). Tests on two 18-years-old prestressed thin walled roof elements. Engineering Structures, 49, 936-946.

CEB (1984) Structural effects of time-dependent behaviour of concrete. St. Saphorin: CEB Bulletin 142/142 bis, Georgi.

CEB-FIB. (2013). fib Model Code 2010, fib bulletin 66 (Vol. 1). Lausanne: Fédération Internationale du Béton/International Federation for Structural Concrete.

Colombo, A., Negro, P. \& Toniolo, G. (2014). The influence of claddings on the seismic response of precast structures: The Safecladding project. In Proceedings of the 2nd European Conference on Earthquake Engineering and Seismology. Istanbul, Turkey, August 25-29, Paper No. 1877.

Crossett, P., Taylor, S., Robinson, D., Sonebi, M., GarcìTaengua, E., Deegan, P. \& Ferrara, L. (2015). The flexural behaviour of SCC beams pre-stressed with BFRP. In Proceedings of the 7th conference of Advanced Composite in Constructions. Cambridge, UK, September 9-11, pp. 62-67.

Dal Lago, A. (1973). Progetto e verifica della deformazione negli elementi precompressi (Design and verification of deformation in pre-stressed members. LIPE_L'Industria Italiana Per 1'Edilizia (Italian Industry for Construction), 4-5-6.

Dal Lago, B., Dal Lago, A., Basso, A. \& Franceschelli, F. (2016a). Exceptional long-span element for industrial roofing. Concrete Plant International, 3, 182-184.

Dal Lago, A. \& Mantegazza, G. (1988). Indagine teorico sperimentale sulla durabilità di strutture in calcestruzzo a ridotto spessore (strutture Ondal) impiegando un additivo liquido a base di silica fume. In Proceedings of the 7th CTE (Collegio dei Tecnici dell'industrializzazione Edilizia) Congress. Venice, Italy, November 4-6.

Dal Lago, B., Taylor, S., Deegan, P., Crossett, P., Sonebi, M., Ferrara, L. \& Pattarini, A. (2016c). Pre-stressing using BFRP bars: An experimental investigation on a new frontier of FRSCC. In Proceedings of the conference on Civil Engineering Research in Ireland 2016, Galway, Republic of Ireland, Paper No. 19.

Dal Lago, B., Toniolo, G., \& Lamperti Tornaghi, M. (2016b). Influence of different mechanical column-foundation connection devices on the seismic behaviour of precast structures. Bulletin of Earthquake Engineering. doi: 10.1007/s10518-016-0010-9.

di Prisco, M., Dozio, D., \& Belletti, B. (2012). On the fracture behaviour of thin-walled SFRC roof elements. Materials and Structures, 46(5), 803-829.

EN 1992-1-1:2005. (2005). Eurocode 2: Design of concrete structures. Part 1-1: General rules and rules for buildings. Brussels: European Committee for Standardization.

Ercolino, M., Magliulo, G., \& Manfredi, G. (2016). Failure of a precast RC building due to Emilia-Romagna earthquakes. Engineering Structures, 118, 262-273.

G+D Computing (2010) Using Strand7 (Straus7) - Introduction to the Strand7 finite element analysis system, 3rd edn. Sydney: Strand7 Pty Limited.
Ghali, A., Favre, R., \& Elbadry, M. (2011). Concrete structures: Stresses and deformations: Analysis and design for sustainability (4th ed.). London: CRC Press.

Gribniak, V., Bacinskas, D., Kacianauskas, R., Kaklauskas, G., \& Torres, L. (2013). Long-term deflections of reinforced concrete elements: Accuracy analysis of predictions by different methods. Mechanics of Time-Dependant Materials, 17, 297-313.

Kim, S. J., Kim, J. H. J., Yi, S. T., Md Noor, N. B., \& Kim, S. C. (2016). Structural performance evaluation of a precast PSC curved girder bridge constructed using multi-tasking formworks. International Journal of Concrete Structures and Materials, 10(Suppl 3), 1-17.

Knight, D., Visintin, P., \& Oehlers, D. J. (2015). Displacementbased simulation of time-dependent behaviour of RC beams with prestressed FRP or steel tendons. Structural Concrete, 3, 406-417.

Lee, C., Lee, S., \& Nguyen, N. (2016a). Modeling of compressive strength development of high-early-strength-concrete at different curing temperatures. International Journal of Concrete Structures and Materials, 10(2), 205-219.

Lee, S., Nguyen, N., Le, T. S., \& Lee, C. (2016b). Optimization of curing regimes for precast prestressed members with early-strength concrete. International Journal of Concrete Structures and Materials, 10(3), 257-269.

Martin, L. D. (1977). A rational method for estimating camber and deflection of precast prestressed members. PCI Journal, 22(1), 100-108.

Migliacci, A. \& Mola, F. (1985). Progetto agli stati limite delle strutture in c.a. (Limit state design of r.c. structures). Vol. 2, Masson editor.

Mola, F. (1997). Long term analysis of R.C. and P.C. structures according to Eurocode2. In Proceedings of the International ECSN (European Concrete Standard in Practice), Copenhagen.

Mola, F. \& Pellegrini, L. M. (2012). The new model for creep of concrete in fip model code 2010. In Proceedings of the 37th conference on Our World in Concrete \& Structures, Singapore.

Pisani, M. A. (2012). Creep analysis of compact cross-sections cast in consecutive stages-Part 1: General method. Engineering Structures, 43, 12-20.

Roller, J. J., Russell, H. G., Bruce, R. N., \& Alaywan, W. R. (2011). Evaluation of prestress losses in high-strength concrete bulb-tee girders for the rigolets pass bridge. $P C I$ Journal, 56(1), 110-134.

Roller, J. J., Russell, H. G., Bruce, R. N., \& Hassett, B. (2003). Effects of curing temperatures on high strength concrete bridge girders. PCI Journal, 48(5), 72-79.

Rosa, M. A., Stanton, J. F., \& Eberhard, M. O. (2007). Improving predictions for camber in precast, prestressed concrete bridge girders. Washington State Transportation Center, University of Washington, Seattle WA, USA, Research Report, Agreement T2695. Task, 68, 1-342.

Sargin, M. (1971). Stress-strain relationship for concrete and analysis of structural concrete sections. Canada: Study $\mathrm{n}$. 4, Solid Mechanics Division, University of Waterloo. 
Singh, B. P., Yazdani, N., \& Ramirez, G. (2013). Effect of a time dependent concrete modulus of elasticity on prestress losses in bridge girders. International Journal of Concrete Structures and Materials, 7(3), 183-191.

Storm, T. K., Rizkalla, S. H., \& Zia, P. Z. (2013). Effect of production practices on camber of prestressed concrete bridge girders. PCI Journal, 58(4), 96-111.
Tadros, M. K., Fawzy, F., \& Hanna, K. E. (2011). Precast, prestressed girder camber variability. PCI Journal, 56(1), 135-154.

Toniolo, G. (2012). SAFECAST project: European research on seismic behaviour of the connections of precast structures. In Proceedings of the 15th World Conference of Earthquake Engineering (WCEE), Lisbon, paper No.1389. 